Delft University of Technology

\title{
Color maintenance prediction for LED-based products
}

van Driel, W.D.; Beijer, J.G.J.; Bikker, J.W.; van Blokland, C.H.M.; Ankomah, C.; Jacobs, B.

DOI

10.1109/EuroSimE.2018.8369875

Publication date

2018

Document Version

Final published version

Published in

2018 19th International Conference on Thermal, Mechanical and Multi-Physics Simulation and Experiments in Microelectronics and Microsystems, EuroSimE 2018

\section{Citation (APA)}

van Driel, W. D., Beijer, J. G. J., Bikker, J. W., van Blokland, C. H. M., Ankomah, C., \& Jacobs, B. (2018).

Color maintenance prediction for LED-based products. In 201819 th International Conference on Thermal, Mechanical and Multi-Physics Simulation and Experiments in Microelectronics and Microsystems,

EuroSimE 2018 (pp. 1-6). IEEE . https://doi.org/10.1109/EuroSimE.2018.8369875

\section{Important note}

To cite this publication, please use the final published version (if applicable).

Please check the document version above.

\section{Copyright}

Other than for strictly personal use, it is not permitted to download, forward or distribute the text or part of it, without the consent of the author(s) and/or copyright holder(s), unless the work is under an open content license such as Creative Commons.

Takedown policy

Please contact us and provide details if you believe this document breaches copyrights.

We will remove access to the work immediately and investigate your claim. 
Green Open Access added to TU Delft Institutional Repository

'You share, we take care!' - Taverne project

https://www.openaccess.nl/en/you-share-we-take-care

Otherwise as indicated in the copyright section: the publisher is the copyright holder of this work and the author uses the Dutch legislation to make this work public. 


\title{
Color maintenance prediction for LED-based products
}

\author{
W.D. van Driel ${ }^{1,2}$, J.G.J. Beijer ${ }^{1}$, J.W. Bikker ${ }^{3}$, C.H.M. van Blokland ${ }^{3}$, C. Ankomah ${ }^{3}$, B. Jacobs ${ }^{1}$ \\ ${ }^{1}$ Philips Lighting, ${ }^{2}$ Delft University of Technology, ${ }^{3} \mathrm{CQM}$ \\ willem.van.driel@philips.com
}

\begin{abstract}
We have seen an increasing number of reported colour maintenance issues in the market when it concerns LED-based products. Besides this, there are also requests to provide products that have $<2$ SDCM colour point changes over lifetime. To understand the mechanisms behind colour maintenance in our LEDportfolio we have developed a calculation method that is able to predict colour maintenance as function of time, construction and material used. The details of that method are described in this paper.
\end{abstract}

\section{Introduction}

LED based luminaires are on the way of replacing traditional incandescent lamps and compact fluorescent lamps in the lighting industry due to many advantages such as energy efficiency improvement and potentially long lifetime. Possible lumen maintenance failure and color shift are two major and important quality and reliability issues except some possible catastrophic (abrupt) failures [1]. Lumen maintenance failure of SSL products is generally characterized by L70 life or 30\% degradation of the lumen output. However, no failure criterion for color shift has been defined specifically in the application field except that ENERGY STAR ${ }^{\circledR}$ program mandates that $\Delta u^{\prime} v^{\prime}$ at 6,000 hours of operation not exceed 0.007 [EPA 2012, 2013][2], which is perhaps the only industry-wide criterion for color shift. It is a reasonable starting point, but may not be strict enough to ensure very high-quality lighting, especially since the lifetimes of LED products routinely far exceed 6,000 hours [3]. Poor color maintenance can be a substantial problem in applications where color quality is important, including museum and gallery lighting, architectural facade lighting, retail display lighting, healthcare lighting, hospitality applications, cove and wall wash lighting, down lighting in commercial and residential applications [4].

Several color-shift complaints originate from the markets, be it indoor or outdoor [5]. Figure 1 depicts two examples.

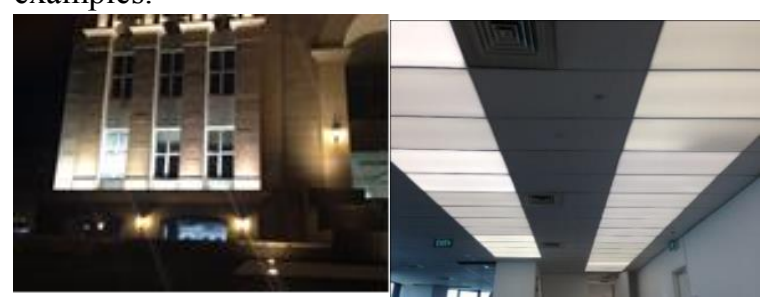

Figure 1: Color shift in outdoor (left) and in indoor (right) applications.
Factors impacting color point stability in LEDs include aging-induced changes in the phosphor, emitter, and encapsulate materials. Higher temperatures will accelerate these degradation mechanisms leading to greater color shift, but the magnitude of the color shift as a function of temperature will vary with packaging materials and manufacturing processes. The resulting direction of color shift depends on the dominant degradation mechanisms occurring in the package, which in turn depends on the packages materials and methods of construction. [6-9].

Some studies have been done on color shift caused by the discoloration of the materials used in the optical system [10-13]. Mehr et al experimentally investigated the color shift of remote phosphor plates made from Bisphenol-A polycarbonate (BPA-PC) and some other materials $[10,11,12]$. Davis et al examined chromaticity shift modes of the PAR38 lamps with four types of builtin LED packages, results shown the chromaticity shift is dominated by the characteristics of the LED, since the optical materials changed little in most samples [13].

Any source of lumen depreciation is likely to be a source of color shift as well, since the light output degradation is not generally completely uniform across the entire spectrum. Different degradation in different parts of the spectrum will inevitably lead to color changes, though the amount of color shift may be small. The most common origins of color shift in LED-based products are given in Table 1. Further details can be found in [14]. Recently these insight are confirmed by the whitepaper on 'LED Luminaire Reliability: Impact of Color Shift' from the Next Generation Lighting Industry Alliance LED Systems Reliability Consortium which was support by Philips Lighting as well [15].

Table 1: Origins of color shift.

\begin{tabular}{lll}
\hline \multicolumn{1}{c}{ Root cause } & \multicolumn{1}{c}{ Examples } \\
\hline Material & $\bullet$ & $\begin{array}{l}\text { Degradation of direct optical path from } \\
\text { LED die to air } \\
\text { Degradation of reflective surfaces } \\
\text { within the LED component } \\
\text { Degradation of the optical materials } \\
\text { with the system, be it MCPET, white } \\
\text { solder resist, Poly Carbonate or } \\
\text { Conternal }\end{array}$ \\
PMMA. & $\begin{array}{l}\text { Contaminations in the direct optical } \\
\text { path such as browning of the optical } \\
\text { path due to VOCs or residual flux after } \\
\text { reflow on the exterior of the LED } \\
\text { package. } \\
\text { Change in the reflective surface } \\
\text { properties of materials within the LED } \\
\text { component, including, for example, } \\
\text { tarnishing of silver. } \\
\text { Carbonization due to lack of oxygen. }\end{array}$ \\
\hline
\end{tabular}




\begin{tabular}{lll}
\hline \multicolumn{1}{c}{ Root cause } & Examples \\
\hline & $\bullet$ & $\begin{array}{l}\text { Sedation of particles onto any optical } \\
\text { surface, for example, onto the silicones. }\end{array}$ \\
Interface & $\bullet$ & $\begin{array}{l}\text { Separation between different material } \\
\text { interfaces such as substrate and optical } \\
\text { path materials. } \\
\text { Material cracking, for example, in the } \\
\text { MCPET reflector due to brittleness. }\end{array}$ \\
\hline
\end{tabular}

Colour shift mechanisms on component, subcomponent and system level are not well understood. Also, the relation between them is far from well understood. Colour shift predictions on system level are extremely difficult and can only be done if the colour shift for its components are mastered properly. To develop a colour shift prediction method, it is important to investigate the colour shift contribution by each individual part. Hence, a novel approach for colour shift investigation based on the so-called view-factor method is proposed as a solution to cover each contribution. To help illustrate this approach, a schematic diagram of light paths for a LED-based product is shown in Figure 1. Each exchange of light in the light paths can be considered as a contribution to colour shift. A further description of this approach, the results and further developments are described in this paper.

\section{Methodology}

Following Figure 1, the suggested modeling approach assumes that a certain fraction of the light emitted or reflected by an optical part is radiated to another part (or even itself again). Each part that reflects light can also give this light a small color shift or spectral change. If the optical model with view-factors turns out to be not accurate enough, then in theory the parts can be divided into several elements each having its own view-factors with the other elements. One must bear in mind that formulas used for the determination of the view-factors assume Lambertian emission and/or reflection.

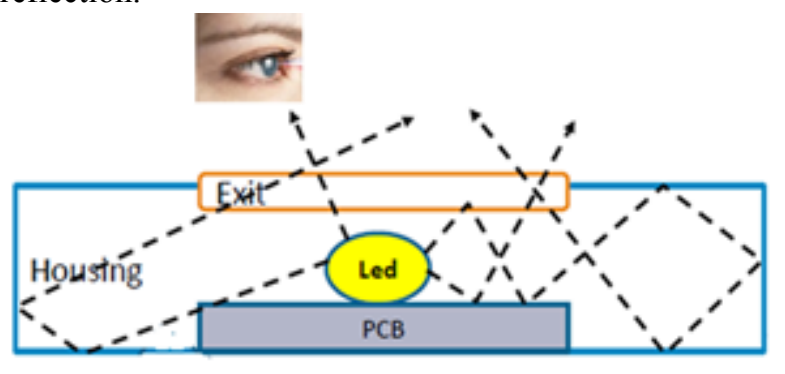

Figure 1: schematic diagram of light paths representing the view-factor approach.

The set of equations describing the light interaction between the 4 optical elements is as follows:

$\left(\begin{array}{l}\Phi_{\text {i to LEDs }} \\ \Phi_{\text {i to pcb }} \\ \Phi_{\text {i to housing }} \\ \Phi_{\text {i to exit }}\end{array}\right)=\left(\begin{array}{llll}F_{L-L} & F_{p-L} & F_{h-L} & F_{e-L} \\ F_{L-p} & F_{p-p} & F_{h-p} & F_{e-p} \\ F_{L-h} & F_{p-h} & F_{h-h} & F_{e-h} \\ F_{L-e} & F_{p-e} & F_{h-e} & F_{e-e}\end{array}\right)\left(\begin{array}{l}\Phi_{\text {ifrom LEDs }} \\ \Phi_{\text {ifrom pcb }} \\ \Phi_{\text {ifrom housing }} \\ \Phi_{\text {i from exit }}\end{array}\right)$
Here the letter i denotes how many interactions (= reflections) the light has already undergone. The matrix with the numbers $\mathrm{F}$ is the view-factor matrix, and as we assume that all light emissions and reflections have Lambertian distribution, the view-factor matrix is independent of $i$. The sum of the elements in each column is equal to 1 . The part "housing" could also be described as the "reflector".

Part of the light hits upon each optical element is also reflected again. This can be expressed in the next equation:

$$
\left(\begin{array}{l}
\Phi_{\mathrm{i}+\text { l from LEDs }} \\
\Phi_{\mathrm{i}+1 \text { from pcb }} \\
\Phi_{\mathrm{i}+1 \text { from housing }} \\
\Phi_{\mathrm{i}+\text { f from exit }}
\end{array}\right)=\left(\begin{array}{lllll}
R_{L} & & & \\
& R_{p} & & \\
& & R_{h} & \\
& & & R_{e}
\end{array}\right)\left(\begin{array}{l}
\Phi_{\mathrm{i} \text { to LEDs }} \\
\Phi_{\mathrm{i} \text { to pcb }} \\
\Phi_{\mathrm{i} \text { to housing }} \\
\Phi_{\mathrm{i} \text { to exit }}
\end{array}\right)
$$

At each reflection the light can undergo a colour change. This colour change can be described in two ways:

1 colour shift Dx and Dy, independent of the colour point (spectrum) of the incoming light

2 spectral change, the reflectivity depends on the wavelength of the light

Method 2 is more realistic, but in that case the spectra of the light needs to be included in the calculations. In case of small colour changes (small changes of the spectrum upon reflection) and low reflectivity's R (fast damping), method 1 can be good enough. Therefore, this method is preferred.

We have the initial condition:

$$
\left(\begin{array}{l}
\Phi_{0 \text { from LEDs }} \\
\Phi_{0 \text { from pcb }} \\
\Phi_{0 \text { from housing }} \\
\Phi_{0 \text { from exit }}
\end{array}\right)=\left(\begin{array}{l}
\Phi_{\text {LEDs }} \\
0 \\
0 \\
0
\end{array}\right)
$$

And then the light coming out of the lamp/luminaire by mean of transmission though the exit window:

$$
\Phi_{\text {from exit }}=\left(1-R_{e}-A\right) \Phi_{\text {to exit }}
$$

Where A stands for absorption and the light is summed over enough $\mathrm{i}$. The transmission of the light can also be accompanied with a colour change of the light. As the light out of the module is also calculated, the approach also gives the optical efficiency as output meaning it can be used to estimate the optical efficiency.

View-factors are related to the geometric design of the product. The formulas for the calculation of the view-factors were found on http://www.thermalradiation.net/indexCat.html. Figure 2 gives the example for luminaire, troffers and such. 


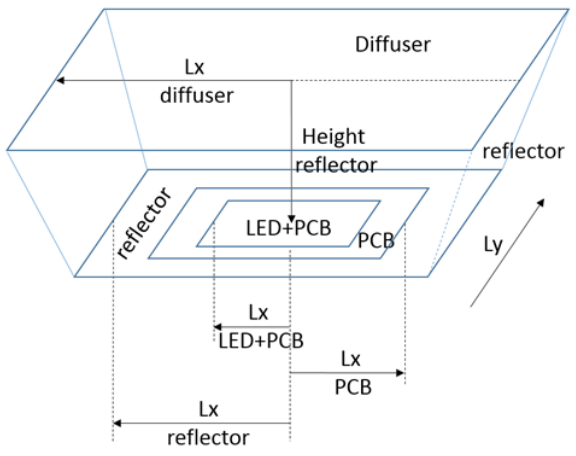

Figure 2: Rectangular product geometry and view-factors.

\section{Carrier}

We have chosen as carrier for the verification of the approach a Certaflux DL-S 6", see Figure 3. The geometry of the DL-S perfectly fits in the axis symmetric" shape of which the view-factors can be calculated by the color shift prediction approach. The view-factor matrix is given in the table below. It shows that the majority of the light coming from the LEDs will go through the diffuser out of the product.

Table 2: View-factor matrix for the carrier product.

\begin{tabular}{ll|llll|}
\multicolumn{2}{l|}{$\begin{array}{l}\text { View-factor } \\
\text { Carrier [\%] }\end{array}$} & \multicolumn{3}{|c}{ From } \\
& & LEDs & PCB & reflector & diffuser \\
\hline \multirow{3}{*}{ To } & LEDs & 0.0 & 0.0 & 0.1 & 0.8 \\
& PCB & 0.0 & 0.0 & 1.1 & 13.2 \\
& reflector & 8.3 & 8.9 & 20.9 & 86.0 \\
& diffuser & 91.7 & 91.1 & 77.9 & 0.0 \\
\hline & SUM & $100.0 \%$ & $100.0 \%$ & $100.0 \%$ & $100.0 \%$
\end{tabular}

In order to verify the approach, the modules were aged at $110^{\circ} \mathrm{C}$ and at $120^{\circ} \mathrm{C}$. At several ageing times the modules were measured for flux, color point and light spectrum in $2 \mathrm{~m}$ spheres. The measurements were done with reflector and with reflector and exit window. Figure 3 shows the color shift of the modules at these different temperatures as function of time.

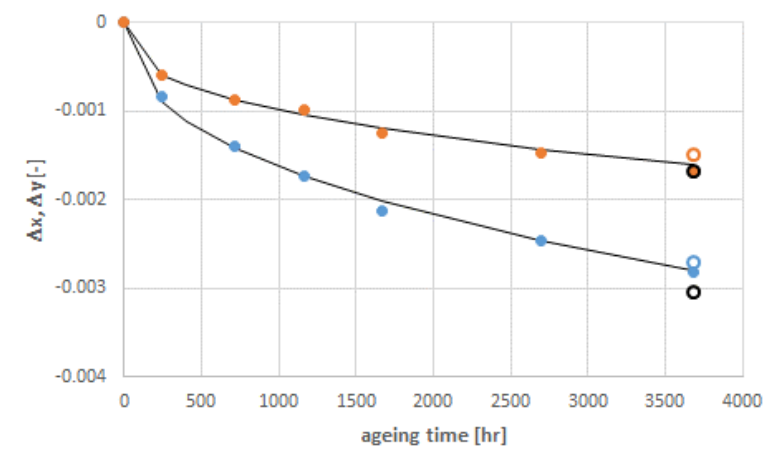

Figure 6: Measured color shifts of the module at 110C (orange) and $120 \mathrm{C}$ (blue), open point is data for no reflector.

In order to model the change of the materials, also the reflector and transmitter materials are tested. The equations used to fit the data are:

$$
\begin{array}{ll} 
& \frac{R_{0}}{R_{t_{0}}}=\frac{R(t=0)}{R\left(t_{\text {eff }}=3682\right)}=f(\lambda) \\
& R\left(t_{\text {eff }}\right)=\frac{R_{0}}{[f(\lambda)]^{\Delta\left(t_{e f f}\right)}} \\
& \Delta\left(t_{\text {eff }}\right)=\left[\frac{t_{\text {eff }}}{t_{0}}\right]^{n} \quad n=1 \\
\text { - } & \Delta t_{\text {eff }}=\Delta t / a_{T} \\
\text { - } & a_{T}=\exp \left[\frac{\Delta H}{R}\left(\frac{1}{T}-\frac{1}{T_{0}}\right)\right]
\end{array}
$$

First equation is the model for the spectrum, the second one is the effect of time and the third one is the Arrhenius equation for the effect of temperature. The results are depicted in Figure 7. A reasonable fit could be obtained following the above approach. The above model is also applied to the measured PCB reflectivity.

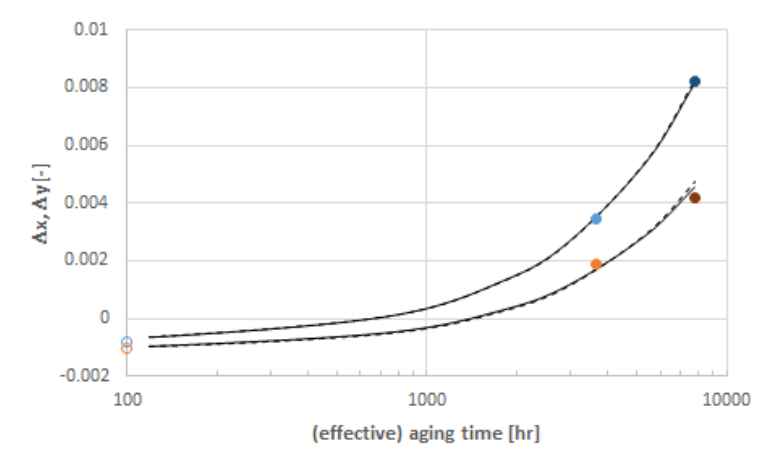

Figure 7: Spectral model fit (dashed lines) of color shifts $x$ (blue) and y (orange) aged at 110C (light) and 120C (dark) and color point fit (solid lines).

For light transmission, we assumed that Fresnel reflections (at uncolored PC) are not accompanied by color shifts, meaning the transmission is corrected for Fresnel reflections by:

$$
\begin{aligned}
& T \approx\left(1-R_{\text {Fresnel }}\right) T_{\text {Fresnel corr. }}\left(1-R_{\text {Fresnel }}\right) \\
& T_{\text {Fresnel corr. }} \approx \frac{T}{1-2 R_{\text {Fresnel }}}
\end{aligned}
$$

Where $T(\alpha, t)$ is the Fresnel corrected transmission depending on the light absorption $\alpha$ and the thickness $t$. An exponential series fit of the transmission quotient (virgin $T_{0}$ divided by aged $T$ ) was chosen:

$$
\frac{T_{\text {Fresnel corr. } 0}}{T_{\text {Fresnel corr. } .\left(t_{\text {eff }}\right)}}=q_{T}=1+\sum_{i} \Delta q_{i} \exp \left(-\frac{\lambda-\lambda_{\text {min }}}{\Lambda_{i}}\right) \text { (7) }
$$

As usual in ageing of plastics, the correlation between ageing time and ageing temperature is described the principle of time-temperature superposition or equivalently introducing the effective time variable as given in (5). If we assume that the transmission quotient $q_{T}$ follows power law, i.e. twice the ageing time gives twice the transmission quotient:

$$
\frac{T_{\mathrm{Fc} 0}}{T_{\mathrm{Fc}}\left(2 t_{e f f}\right)}=\frac{T_{\mathrm{Fe}}(0)}{T_{\mathrm{Fc}}\left(t_{e f f}\right)} \frac{T_{\mathrm{Fc}}\left(t_{\text {eff }}\right)}{T_{\mathrm{Fc}}\left(2 t_{\text {eff }}\right)}=q_{T}\left(\Delta t_{e f f}\right) q_{T}\left(\Delta t_{e f f}\right)=\left[q_{T}\left(\Delta t_{e f f}\right)\right]^{2}(8)
$$


More general:

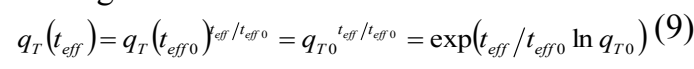

The effect of thickness is evaluated using the Lambert Beer law. If we assume that the absorption coefficient is constant through the thickness $h$ of the plate, then the Fresnel corrected transmission can be translated into an absorption coefficient $\alpha$ :

$$
T_{\text {Fresnel corr. }}=\exp (-\alpha h) \Leftrightarrow \quad \alpha=-\ln \left[T_{\text {Fresnel corr. }}\right] / h(10)
$$

The Fresnel corrected transmission data and fit, shown earlier, can with this formula be translated into the absorption coefficient; see next two figures. As $\alpha$ is independent of the thickness, the above equation can be used to calculate the Fresnel corrected transmission at other thicknesses:

$$
T_{\text {Fresnel corr. }}(h)=\exp \left(\ln \left[T_{\text {Fresnel corr. }}\left(h_{0}\right)\right] h / h_{0}\right)=\left[T_{\text {Fresnel corr. }}\left(h_{0}\right)\right]^{h / h_{0}}
$$

Combining thickness and effective ageing time the equation for the transmission $T$ becomes:

$$
T=\left(1-2 R_{\text {Fresnel }}\right)\left[\frac{T_{\text {Fresnel corr. } 0}}{q_{T 0} t_{\text {eff }} / t_{\text {eff }}}\right]^{h / h_{0}}
$$

The resulting fit on the exit window material, in this case polycarbonate, is shown in Figure 8.

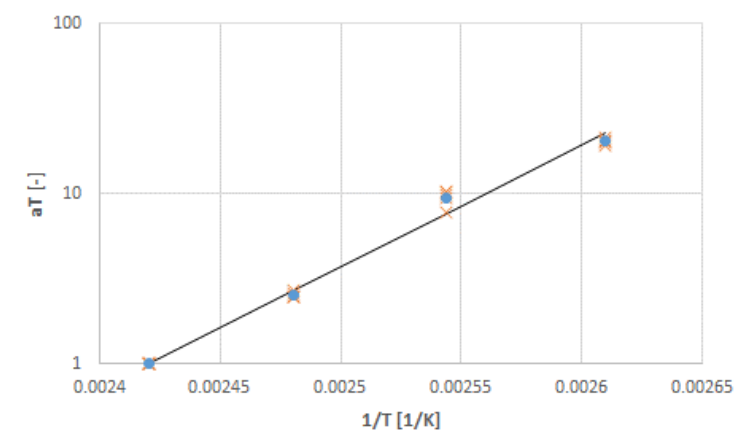

Figure 9: Time temperature relation of the ageing of the clear $P C$.

With the parts (LED, PCB, reflector, exit window/optics) characterized, the "light transformation" of the parts can be combined with viewfactors. The view-factors being a function of the geometry, as mentioned before. A series of 12 aging experiments are performed to verify the approach. This measured colour shift in these experiments is shown in Figure 10 (top). Again, aging gives a blue shift for the LED and a yellow shift for the other components. The predicted colour shift is shown in Figure 10 (bottom). Clearly the measured colour shifts are further apart than the calculated colour shifts. Comparing aged and unaged reflector the measured colour shift difference is even bigger than the expected colour shift difference of the reflector. Therefore, it is likely that the light recycling in the carrier product is larger than now used in the calculations. All 12 measurements data and model results are shown in Figure 12. The trends are described as acceptable. As can be observed the modelled shift in $\mathrm{x}$ is bigger than measured for the three lower points, that is experiment 1,7 and 12, which are products with unaged exit window.
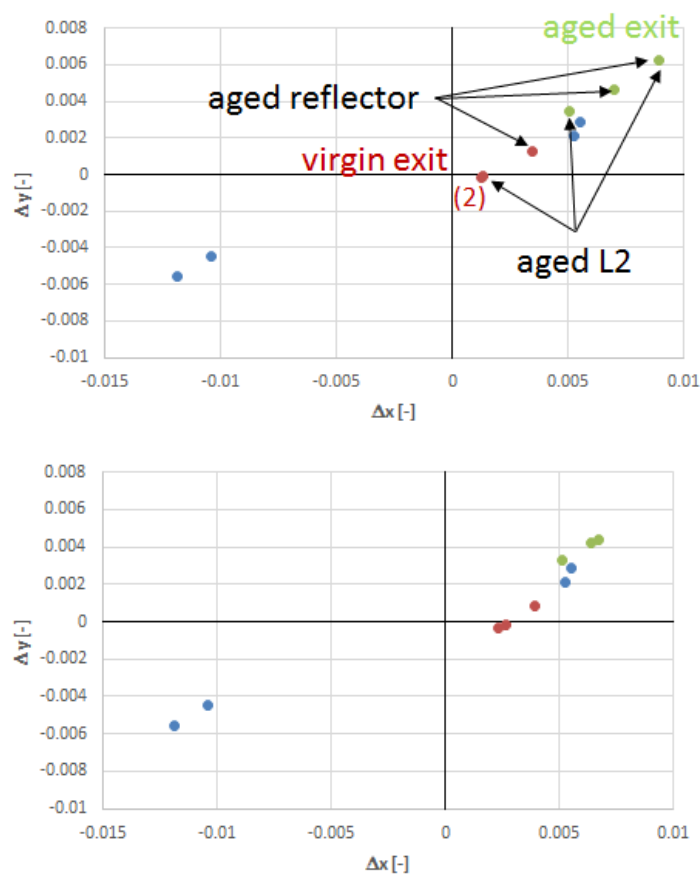

Figure 1: Figures with the carrier color shift (LED engine color point $=0$ ), top figure shows $2 \mathrm{~m}$ sphere data and bottom figure shows calculation results.
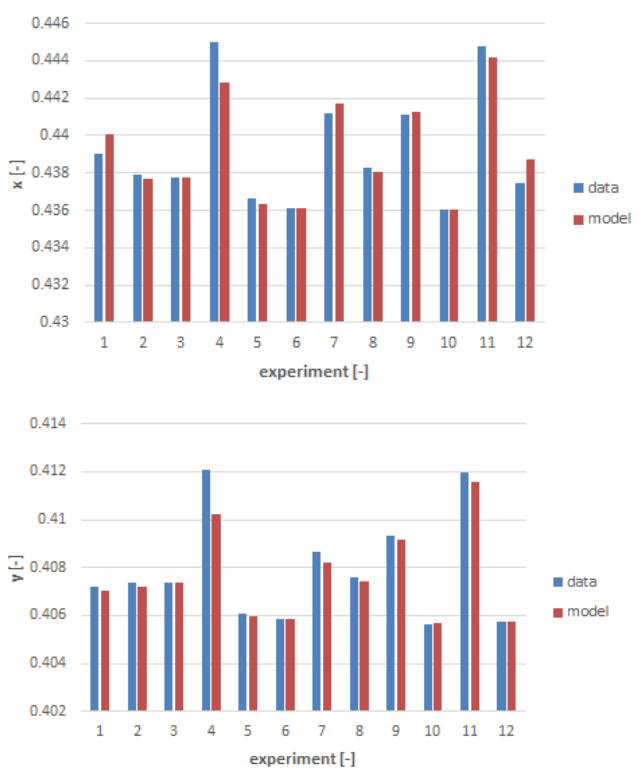

Figure 12: Comparison of measured and modelled $x$ and $y$ color coordinates for the 12 experiments.

With the given color shift model, predictions of both the lumen decay as the color shift are possible. Now the temperature dependent (effective time) models for color shift, lumen decay, reflection and transmission change are used. Figure 13 show the color points of the carrier product as function of time at elevated temperatures. 
The first pair figures show the effect of temperature and the second pair figures show the effect of the different parts. The red lines in the uv' shift and lumen decay graphs show the currently applied lifetime limit: lumen decay $80 \%$ and color shift $7 \mathrm{SDCM} \approx 0.007$ in uv'. From the figure it can be seen that the LED color shift starts faster than the color shift due to yellowing of the PCB, reflector and exit window. In the end the yellowing "wins" even with $90{ }^{\circ} \mathrm{C}$ LED temperature and $70{ }^{\circ} \mathrm{C}$ reflector and exit window temperature. As the LED color shift is towards blue, the DLS color point first moves a bit towards blue and later moves in the opposite direction towards yellow. The result is that if the LEDs would give a fixed color (no aging) the color shift of the product will be larger.

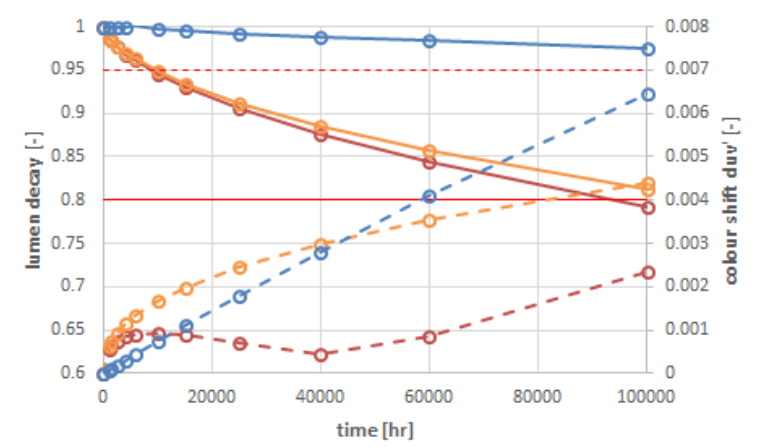

Figure 13: Calculated uv' color shift (dotted line) and lumen decay (solid line) vs time with LEDs 100C, PCB 90C, reflector \& exit window $80 C$ and with red: all parts aging, orange: only LED aging, blue all but LED aging.

\section{Real case}

As a real case we select a typical indoor office troffer. It is $600 \mathrm{~mm}$ in length and has 1 line of LEDs inside, see Figure 14. Table 3 depicts the view-factor matrix. The failure criterium for lumen decay is set at $80 \%$ from initial values, color shift at 6 SDCM.

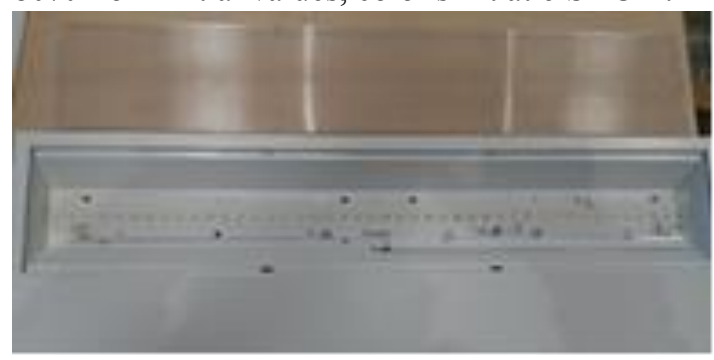

Figure 14: Indoor office troffer.

Table 3: View-factors for the indoor troffer.

\begin{tabular}{ll|llll|}
\multicolumn{2}{l|}{$\begin{array}{l}\text { View-factor } \\
\text { troffer [\%] }\end{array}$} & \multicolumn{4}{|c}{ From } \\
& & LEDs & PCB & reflector & diffuser \\
\hline \multirow{3}{*}{ To } & LEDs & 0.0 & 0.0 & 1.7 & 15.0 \\
& PCB & 0.0 & 0.0 & 2.5 & 21.1 \\
& reflector & 7.8 & 8.4 & 11.2 & 63.9 \\
& diffuser & 92.2 & 91.6 & 84. & 0.0 \\
\hline & SUM & $100.0 \%$ & $100.0 \%$ & $100.0 \%$ & $100.0 \%$
\end{tabular}

The temperature within the products are measured using thermocouples and found to be:

- The LED temperature increases with $60 \mathrm{C}$ when on (HP LED operating at $700 \mathrm{~mA}$ ).

- The optical materials increase with 50C when on (exit window, housing and PCB).

The above is denoted as nominal conditions. The resulting lumen decay and color shift are depicted in Figure 14. When one asks which criterion is limiting, lumen decay $(80 \%)$ or color shift (7 SDCM), then the left figure shows that lumen decay is most critical. But if one thinks of strict spec products with only 2 SDCM color shift then the allowed color shift occur around $60 \mathrm{khrs}$, way before the time to reach $80 \%$ lumen maintenance values. Now imagine that the optical material of the exit is just $+5 \mathrm{C}$ higher in temperature, e.g. due to exposure to the sun. The resulting color shift is depicted in Figure 15. This increased temperature of the exit window accelerates the yellowing and the total system level color shift now exceeds the value of 6 SDCM. It shows that the balance between lumen decay and color shift is quite tight.
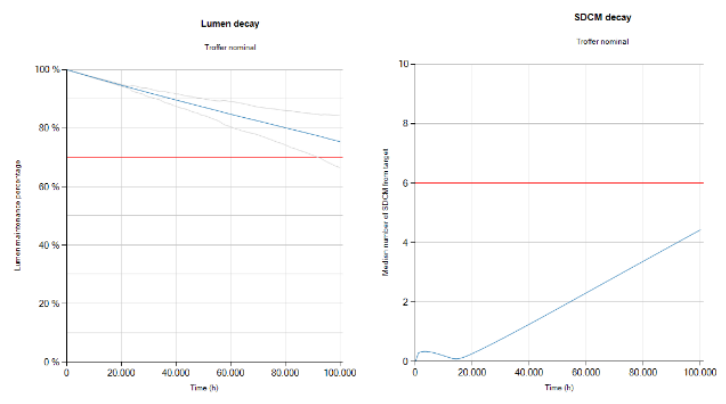

Figure 14: Nominal case, lumen decay (left) vs color shift (right) as function of operation time.

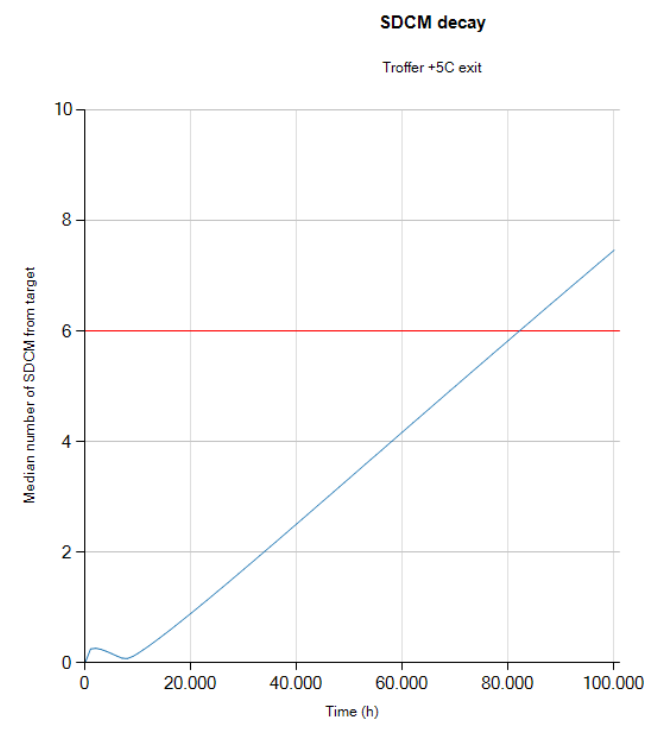

Figure 15: Exit window +5 C of nominal values; color shift as function of operation time. 


\section{Conclusions and recommendations}

A method was developed that can estimate the color shift of a LED-based product, based on the color shift of the LEDs and the aging / yellowing of the PCB and optical materials. A too large color shift is considered as a reliability issue. To estimate the color shift, one must know:

- LED properties: color point and color point change in time, depending on the LED temperature.

- PCB, reflector and exit window properties: color change by reflection (and transmission) of LED light on the $\mathrm{PCB}$, reflector and exit window, also time and temperature dependent. In case of the exit window.

- Geometry: the geometry determines the light exchange between the different parts of the LED lighting module.

The developed approach uses so called view-factors to calculate the light exchange between the parts. This is an approximation of the reality as it assumes Lambertian distribution of reflected light. Also it is assumed that the change of the light (color / spectrum) after reflection at $\mathrm{PCB}$, reflector or exit window does not affect successive reflections. In other words: the color shift at an interface is independent of the history of the light. To further develop the method it is recommended that:

- The optical behavior of translucent optical windows is further investigated as this part is difficult to measure and model and it gives the largest contribution to the color shift (of the optical parts)

- Full (Lighttools) color shift simulations are performed for the presented carrier and real case products, to further validate / improve the color shift method.

- For other LED-based products (spots, troffers, modules, etc.) it is recommended to check that the LED color shift is towards blue, as this will compensate the yellowing of the optical parts.

\section{Acknowledgments}

This work was supported by the European project "IoSENSE: Flexible FE/BE Sensor Pilot Line for the Internet of Everything". This project has received funding from the Electronic Component Systems for European Leadership Joint Undertaking under grant agreement No 692480. This Joint Undertaking receives support from the European Union's Horizon 2020 research and innovation programme and Germany, Saxony, Austria, Belgium, Netherlands, Slovakia, Spain.

\section{References}

[1] Van Driel W.D. and Fan X.J, Solid State Lighting Reliability: Components to Systems. New York:Springer, 2013

[2] Eligibility Criteria - Version 1.3, ENERGY STAR Program Requirements for Solid State Lighting Luminaires,

http://www.energystar.gov/ia/partners/product_specs/pro gram reqs /Solidstate Lighting Program Requirements.pdf.

[3] Michael Royer, Ralph Tuttle, Scott Rosenfeld, Naomi Miller, Colour Maintenance of LEDs in Laboratory and Field Applications, Gateway demonstrations, Prepared for Solid-State Lighting Program, September 2013

[4] LJ Sandahl, KA Cort, KL Gordon, Solid-State Lighting: Early Lessons Learned on the Way to Market, Prepared for the U.S. Department of Energy, September 2013

[5] M. Royer, R. Tuttle, S. Rosenfeld, and N. Miller, Color maintenance of LEDs in laboratory and field applications, DOE Gateway Report, September 2013. Available at http://apps1.eere.energy.gov/buildings/publications/pdfs/s sl/2013 gateway colour maintenance.pdf accessed November 28, 2015.

[6] Norman Bardsley, Monica Hansen, Lisa Pattison, Morgan Pattison, Kelsey Stober, Victor Taylor, Jeffrey Tsao, Mary Yamada, Solid State lighting R\&D Plan, Prepared for Solid-State Lighting Program Building Technologies Office,Office of Energy Efficiency and Renewable Energy U.S. Department of Energy, Jun 2016

[7] Ralph C. Tuttle, LED Package Reliablity-Colour point Stability, 2015 , https://cms.doe.gov/sites/prod/files/2015/03/f20/tuttle_co lourshift_sanfrancisco2015.pdf

[8] Huang J, Golubović DS, Koh S, Yang D, Li X, Fan X, Zhang GQ, Rapid degradation of mid-power white-light LEDs in saturated moisture conditions, IEEE Transactions on Device and Materials Reliability 99(2015).

[9] N. Narendran, Y. Gu, J.P. Freyssinier, H. Yu, L. Deng, Solid-state lighting: failure analysis of white LEDs, Journal of Crystal Growth 268 (2004) 449-456.

[10] M. Yazdan Mehr, W.D. van Driel, H. Udono, G.Q. Zhang, Surface aspects of discolouration in Bisphenol A Polycarbonate (BPA-PC), used as lens in LED-based products, Opt. Mater. 37 (2014)155-159.

[11] M. Yazdan Mehr,W.D. van Driel, K.M.B Jansen, P. Deeben, G.Q. Zhang, Lifetime Assessment of Plastics Lenses used in LED-based Products, Microelectronics Reliability 54 (2014) 138-142.

[12] M. Yazdan Mehr, W.D. van Driel, G.Q. Zhang, Progress in Understanding Color Maintenance in SolidState Lighting Systems, Engineering, 1 (2015) 170-178

[13] J. Lynn Davis, Joseph Young, and Michael Royer, Caliper Report 20.5: Chromaticity Shift Modes of LED PAR38 Lamps Operated in Steady-State Conditions, Prepared for Solid-State Lighting Program (Building Technologies Office, Office of Energy Efficiency and Renewable Energy and U.S. Department of Energy) February 2016

[14] Van Driel W.D. and Fan X.J, Solid State Lighting Reliability: Components to Systems - Part II. New York:Springer, 2017.

[15] Next Generation Lighting Industry Alliance LED Systems Reliability Consortium, LED Luminaire Reliability: Impact of Color Shift, April 2017. 